\title{
EDUCAÇÃO, TRABALHO E CIDADANIA
}

BASTOS, Manoel de Jesus ${ }^{1}$

BASTOS, Manoel de Jesus. Educação, Trabalho e Cidadania. Revista Científica Multidisciplinar Núcleo do Conhecimento. Ano 02, Ed. 01, Vol. 14, pp. 98-109 Janeiro de 2017 ISSN:2448-0959

\section{RESUMO}

Diante de tantas desigualdades sociais, políticas e econômicas a que se vivencia, atualmente, a educação é a única fonte que pode oferecer alternativas para uma saída satisfatória da sociedade. A construção da tão almejada cidadania e a qualificação para o trabalho, só serão efetivadas se for levado em consideração este grande e robusto pilar básico que tem condições, suficientes, para contribuir com a formação de novas gerações justas e equilibradas. Contudo, investir na educação é, ao mesmo tempo, apostar numa sociedade desmascarada, ativa, compromissada com o bem estar social, cumpridora dos deveres que lhes estão incumbidos e ciente dos direitos que Ihes estão garantidos na lei. Recentes pesquisas tem mostrado a realidade da educação no Brasil, sinalizando a necessidade de melhoramento no que diz respeito a sua qualidade. Acredita-se que os problemas não são oriundos das metas a serem cumpridas, mas na falta de rigorosidade nos resultados pedagógicos. Até que existe planejamentos, porém, didaticamente, ineficazes. Os resultados pretendidos nunca são consumados conforme se planejou. Com as etapas da educação básica fragmentadas, o problema tende a persistir ao longo dos estudos, desalicerçando toda a estrutura formativa do indivíduo.

Palavras-Chave: Educação, Cidadania, Sociedade, Indivíduos, Qualidade.

\footnotetext{
${ }^{1}$ Formado em Normal Superior pela UESPI (Universidade Estadual do Piauí), Pósgraduado em Supervisão Escolar pela Faculdade de Teologia Hokemãh Fateh e Mestrando em Educação pela Anne Sullivan University.
} 


\section{INTRODUÇÃO}

Analisando as acentuadas desigualdades sociais, políticas e econômicas no mundo, observa-se que a globalização vem sendo acelerada de forma muito rápida, inclusive pelo sistema capitalístico que tem grande fomentação pela exploração do lucro arrancado das entranhas da população mundial, favorecendo o crescimento da pobreza e o surgimento das desigualdades e da exclusão social. Enquanto o acumulativo de riquezas vem sendo um processo dinâmico, organizado e centralizado à elite, a educação tem sido badalada nos palanques, nos congressos e nos fóruns como a saída dos mais aviltantes problemas sociais que jamais deixarão de existir. A declaração: "educar para o pleno exercício da cidadania", tornou-se algo utópico e, para reverter esse quadro nebuloso é preciso que se reflita e assuma esse compromisso social.

Todavia, as políticas educacionais necessitam ser repensadas para a mudança positiva da prática pedagógica e da formação do cidadão. Uma reflexão aprofundada para a realização de novas ações, à respeito do assunto, poderia sinalizar a solução almejada. A educação precisa desvincular-se do faz de conta e partir para ações consolidadas, evidenciando a sua emancipação e formando cidadãos capazes de atuar como agentes de suas próprias histórias. Aliás, o poder de manipular certas ações e decisões políticas governamentais da educação tem empecilhado na efetivação da verdadeira cidadania.

A relação entre educação e trabalho deve ter, imprescindivelmente, um estreitamento observável, uma vez que a escola qualifica o indivíduo para o melhor desempenho de suas atividades, ou seja, é um tema que vem sendo discutido por profissionais da área, atribuindo mecanismos para a sua melhoria.

Educação e trabalho são direitos fundamentais previstos no artigo 6ำ da Constituição Federal, reconhecidos pelo Estado com o intuito de proteger e proporcionar a qualidade e tratamento fraterno da sociedade. 
Todavia, a educação poderá contribuir na superação da marginalidade a partir do momento em que consolidar a formação de indivíduos eficientes e capazes de oferecerem a sua parcela contributiva ao aumento da produtividade social.

\section{EDUCAÇÃO TRABALHO E CIDADANIA}

É absolutamente correto afirmar que nem sempre a educação vem atender as exigências emancipadoras dos indivíduos, uma vez que a pedagogia tecnicista é gerada em torno da profissão e da produtividade e jamais se preocupou com a marginalidade e com a abolição da ignorância e com o cumprimento do exercício da cidadania.

O ensino técnico tem objetivos específicos voltados à formação de recursos humanos com almejos na empregabilidade e na produção tecnológica. O desemprego, na maioria das vezes, é consequência do despreparo ao mercado de trabalho, pois uma empresa dispensa o interesse de contratar indivíduos que não possuem habilidades para a acelerada produtividade esperada no mercado.

A educação está contribuindo para superar o problema da marginalidade na medida que formar indivíduos eficientes, portanto, capazes de darem sua parcela de contribuição para o aumento da produtividade da sociedade. (SAVIANNI, 1995, P. 25)

No entanto, é necessário que as instituições educacionais reflitam e ajam com novas ações, visando a transformação da globalização em um processo igualitário em todas as esferas culturais, sociais e políticas. É inadmissível que a educação tenha, como papel principal, a formação de seres humanos como objetos aptos ao mercado de trabalho, quando a sua verdadeira tarefa é formar cidadãos críticos, conscientes e capazes de produzir, ou seja, a sua incumbência, como compromisso social, é a de libertar e não alienar.

A educação vem, ao longo dos anos, passando por várias transformações as quais, nem sempre, significam progresso, uma vez que certas inovações não atendem os 
almejos de uma sociedade justa, como dizia Paulo Freire, (1987, p. 158): "Se todo desenvolvimento é transformação, nem toda transformação é desenvolvimento".

É preciso, portanto, que se efetive a prática pedagógica, acionando uma política voltada, exclusivamente, para a formação democrática, cidadã e libertadora.

"Não basta formar indivíduos, é preciso saber para que tipo de sociedade, para que tipo de prática social o educador está formando cidadãos". (DUARTE, 1999, p. 25)

\section{RELAÇÃO ENTRE TRABALHO E EDUCAÇÃO}

Desde a extemporaneidade, a humanidade já buscava, no trabalho, alternativas para satisfazer as suas necessidades básicas, mas com um certo equilíbrio. Com o passar dos anos, as relações sociais tornaram-se mais complexas, tornando as suas relações de trabalho também complexas, proporcionalmente. Na contemporaneidade há uma certa deseducação em relação ao homem e a natureza, tendo em vista, a fomentação ou a imensurável ganância pelo enriquecimento rápido. O homem está indo além dos seus limites destruindo-a e ele mesmo. Entende-se que o trabalho está sendo considerado desumano, imoral e responsável pelas consequências da exclusão social.

De certa forma, o trabalho deve dignificar o homem, refletindo nele a sua própria identidade, como ser criador, transformador e organizador da sociedade a que pertence. O trabalho é a característica que o diferencia dos outros seres, condicionando o seu próprio modo de vida e desenvolvendo-o de acordo às suas relações com a sociedade na qual está inserido. No mundo capitalista é diferente, porque o trabalho do homem não é visto como algo que satisfaz suas carências, mas como fonte acumulativa de riquezas, trazendo, como consequências, a transformação negativa da natureza e a degeneração ambiental. Para tanto, criaram máquinas sofisticadas que substituíram os trabalhos manuais, com alta produção e em curto espaço de tempo. 
A educação tem um papel muito importante no que diz respeito ao mercado de trabalho, independentemente, de cursos profissionalizantes ou não. Ela ajuda a manter as pessoas empregadas, além de possibilitar a facilitação do emprego.

Em nosso país o setor educacional também passou por essas transformações, quando buscou-se o ensino técnico para a qualificação do trabalho, excluindo, de certa forma, milhares de trabalhadores que, na ótica empresarial, não estão preparados à produzir qualitativa e quantitativamente. Enquanto isso, os considerados desqualificados prestam os seus duros, porém importantes, serviços recebendo apenas o mínimo para a manutenção da própria sobrevivência.

As relações de trabalho estão, cada vez mais, abrangentes e os trabalhadores desmascarando seus medos e unindo forças através dos Sindicatos ou Associações para defender os seus direitos. O crescimento tecnológico também tem avançado assustadoramente em todos os setores e em todos os recantos do planeta, modificando o dia-a-dia das pessoas em busca de uma produção rápida e qualitativa.

De maneira que é através da realização de suas atividades cotidianas que o homem tenta expressar sua identidade de verdadeiro ser humano.

\section{A EDUCAÇÃO COMO PILAR BÁSICO}

O sistema educacional tem apresentado uma infinidade de estratégias para a melhoria do seu currículo, por acreditar que a educação é um dos pilares que pode oferecer condições seguras para a mudança social ascendente, porém é necessário que esse currículo não fique restrito a professores, mas que, segundo MOREIRA e CANDAU, seja entendido como um conjunto de ações pedagógicas com intenções educativas, ou seja, é dever de todos aqueles que almejam e buscam uma sociedade desmascarada e alerta.

É preciso, ainda, entender que o processo ensino-aprendizagem, não se limite ao repasse de conteúdos a serem ensinados e aprendidos, tampouco a memorização por parte do aluno, pois tudo que é repetição é cansativo e desgastante, mas um 
conjunto de atitudes que contribuam na construção de saberes. A nomenclatura "ensino-aprendizagem" sinaliza uma interdependência entre ambos, uma vez que esses caminham paralelamente e dependem da democracia dos questionamentos e das reflexões para que se efetive os objetivos propostos. Tanto o professor quanto o aluno devem estar envolvidos no processo, continuamente, questionando, refletindo, desenvolvendo capacidades cognitivas, relacionando conhecimentos e utilizando-os na construção de atitudes e valores. Pelo contrário seria inútil, inexpressivo e dissaboroso, uma vez que o educando precisa ser despertado e instigado pelo novo e pelo poder de atitudes criadoras, dentro dos seus próprios conhecimentos.

O educador e psiquiatra, Içami Tiba, em seu Livro "Quem Ama Educa”, menciona que as aulas devem ser como alimento, temperado, balanceado e preparado com carinho, para motivar a fomentação.

Para se ter uma educação de qualidade e contribuir coma boa formação do cidadão, capaz de transformar a sociedade, positivamente, é preciso desapegar dos livros sem, no entanto, ignorá-los, vestir-se humildemente e admitir que ser professor não é ser dono da verdade, o sabe tudo, mas um mediador de ideias e um viabilizador da construção de conhecimentos. É preciso fazer menção à integração dos educandos em sala de aula, conservando a criatividade, a participação e a democracia de concepções. O sucesso do ensino-aprendizagem aparece a partir da troca de experiências, vinculadas ao currículo, onde cada um expõe a sua concepção através do diálogo, do debate etc.

Por sua vez, o professor deve estar ciente da importância de um planejamento possível, sem utopias, esforçando-se pelo seu cumprimento na íntegra. É com essa segurança que o ensino-aprendizagem acontece, sobretudo, quando se perde o medo, o pessimismo e acredita-se na sua consolidação de fato. Aliás, não haveria nenhum trabalho pedagógico com resultados positivos, se não fosse permitida a discussão entre os que dele fazem parte, como professores, alunos, pais de alunos etc. 
No trabalho pedagógico existe as seguintes opções: esforçar-se para ser mediador entre as informações e os alunos, desenvolvendo um processo de aprendizagem socializadora, crítica e democrática ou, simplesmente, acomodar-se oferecendo um serviço alienado e voltado aos interesses capitalísticos.

A boa escola será aquela que desperte e estimule a consciência crítica, que não deforme a história, que não ignore os vastos espaços da realidade social, que não oculte ou desqualifique o conflito, enfim, que não reprima, que liberte. (TAMARIT, 1996, p. 61)

O verdadeiro papel da escola é preparar o estudante para o exercício social na qual se encontra inserido, lutando pela igualdade e justiça, abolindo a exclusão de muitos indivíduos. Em hipótese alguma, poderia mudar-se a sociedade, se a educação não for reformulada, pensada e realizada pela própria sociedade. Para a construção da tão sonhada sociedade justa, é preciso que se ofereça uma educação libertadora, possibilitando a participação crítica e consciente do aluno no processo do ensinoaprendizagem, desalienando-o do sistema radicalizado. Infelizmente, poucos são os que tem se esforçado pela construção de uma sociedade justa e equilibrada, a través da educação, quando a sua evolução se dá a partir dos anseios de muitos.

"Só se pode ter uma nova sociedade (...) se for modificada a educação da geração mais jovem. Contudo, a nova sociedade é a força necessária para a mudança na educação". (FERGUSON, 1992, p. 265)

\section{A FORMAÇÃO DO SER HUMANO}

A escola é a instituição que desempenha um papel fundamental na formação do sujeito, onde a aprendizagem passa a ser um acúmulo de conhecimentos científicos norteadores do crescimento e da participação dele na sociedade. O conhecimento é imprescindível na sua vida para que ele se sinta valorizado e preparado para os desafios da vida no cotidiano. Segundo DUARTE, (1999), esse saber cotidiano não é o mesmo para todos os indivíduos, cada um tem um saber particular em decorrência de suas experiências de vida, que são diversificadas. O indivíduo deve buscar na $\mathrm{RC}: 6692$

Disponível em: https://www.nucleodoconhecimento.com.br/educacao/educacao-trabalho-ecidadania 
escola os seus próprios ideais, a liberdade de expressão e o recheio dos seus sonhos, rumo a cidadania a que objetivam.

Há uma relação entre a alegria necessária à atividade educativa e a esperança. A esperança de que professores e alunos, juntos possam aprender, ensinar inquietar, produzir e juntos resistir os obstáculos à alegria. (FREIRE, 2002, p. 80)

Todavia, cabe a escola transparecer a importância da formação do indivíduo para que, assim, ele possa saber usar o seu conhecimento de forma correta e contributiva na sociedade a que pertence, pelo contrário, não estaria cumprindo com o seu papel de instituição educadora. Mesmo em meio ao avanço tecnológico, mesmo diante de tanto progresso, a educação é a área considerada a mais importante nas suas mais diversas formas e esferas para a condução e efetivação da cidadania, pois a capacidade de criar, entender e libertar só serão consumadas a partir do momento em que for feito menção à mesma.

O indivíduo constrói conhecimento, adquire liberdade e consolida ética, entre outros princípios afins, através da educação. Esta, dá-lhe todas as garantias da construção de uma sociedade mais justa e mais humana, onde os sonhos e as possibilidades sejam respeitados de maneira que cada indivíduo possa desenvolver a sua própria forma de ensinar e aprender, como verdadeiro agente transformador.

Minha segurança não repousa na falsa suposição de que sei tudo, de que sou o maior. Minha segurança se funda na convicção de que sei algo e de que ignoro algo a que se junta a certeza de que posso saber melhor o que já sei e conhecer o que ainda não sei. (FREIRE, 2002, p. 153)

Considerando a educação como a base sólida para a formação e essencial à construção da cidadania, torna-se imprescindível que a mesma seja realizada de maneira continuada e permanente, deixando apenas de ser qualificativa para 0 trabalho, mas para o exercício legal da cidadania. 


\section{A EDUCAÇÃO NA CONSTRUÇÃO DA CIDADANIA}

As leis da educação mencionam, explicitamente, que a formação do indivíduo faz-se necessário para o exercício da cidadania. De modo, que não há outro caminho, senão o da educação, para que se adquira conhecimentos necessários ao cumprimento dos deveres e o requerimento dos devidos direitos, previstos constitucionalissimamente. O desmascaramento, o senso crítico, o poder de decisão e produção, são resultados de uma educação consciente que busca a construção da legítima cidadania. Mas, afinal, qual é a importância da cidadania e como deve ser exercida pelos indivíduos? A cidadania é imprescindível em meio a sociedade, e a pessoa que a cumpre, está em plena posse dos seus direitos civis e políticos, previstos na Constituição, para com o estado livre e sujeita aos deveres que Ihes são incumbidos. Sendo assim, entendese que ser cidadão implica no exercício livre dos direitos e deveres de modo que sempre prevaleça o bem comum.

Por sua vez, as leis representam uma gama de normas e regras sociais a serem cumpridas, com intenções de oferecerem aos cidadãos uma vida mais agradável e, excepcionalmente, produtiva uns com os outros, ou seja, elas são, analogicamente, um conjunto de andaimes que suporta e enquadra as maneiras de realizar algo dentro da sociedade. Contudo, descumprir com a cidadania na escala social é, ao mesmo tempo, descumprir com as leis que Ihe dão autenticidade. Aliás, esse déficit já é realidade em quase todos os povos e nações, com exceção a requerimentos dos direitos que não deixam de ser realizados.

No entanto, cabe a educação possibilitar, cientificamente, a construção da verdadeira cidadania que será indispensável ao indivíduo para viver, decentemente, na sociedade. A Declaração Universal dos Direitos Humanos, rege, em nível mundial, a respeito da efetivação e cumprimento.

Há necessidade de se caminhar para uma cidadania multicultural planetária, construindo relações humanas baseadas na convivência emancipatória, amorosa, 
sensível e criativa, fortalecendo a cidadania, a democracia e o carácter público da educação. (Carta do Porto, Instituto Paulo Freire, 2004)

Todavia, há a reafirmação nesta carta de que a cidadania, o conhecimento, a ciência e a tecnologia são direitos de todos e que são adquiridos na escola, a qual exerce um papel importantíssimo para a vida na sociedade, uma vez que a mesma é a fornecedora de amplos horizontes nos quais os indivíduos inscrevem suas vidas e efetivam as suas perspectivas. Segundo Oliveira Martins, a escola é a agente de mudança e fator de desenvolvimento (...) tem que se assumir basicamente não só como potenciador de recursos, mas também um lugar de abertura e de solidariedade, de justiça e de responsabilização mútua, de tolerância e respeito, de sabedoria e de conhecimento. (1992: 41)

Enfim, a escola pública vem desenvolvendo uma tarefa crucial na educação para a cidadania, pois ela acolhe a todos e viabiliza a vida na cidade democrática.

\section{EDUCAÇÃO DEVER DA FAMÍLIA}

A família é o primeiro espaço onde deve ser principiada a construção da educação para a cidadania, tendo em vista, ser ela a matriz da socialização na vida dos indivíduos. No entanto, ela está incumbida de uma das tarefas mais importantes na vida dos seus filhos, que é o de apregoar os princípios da socialização, da honestidade, do respeito e da tolerância, dentro das normas legítimas previstas nas leis.

E por ser o alicerce, a base da construção educativa, a família deve proporcionar aos seus filhos, de modo sistemático e afetivo, trampolins que possibilitem os seus desenvolvimentos cognitivos e culturais. Logicamente, não se poderia construir cidadania se não se considerasse, a priori, a educação, que não deixa de ser papel berçal e exclusivo da família que tem sonhos e que cumpre com as suas obrigações com responsabilidade e com muito amor, apostando em elementos que serão importantes à vida em comum. 
É sabido que a formação de nível pessoal e social, tanto no sentido ético como estético, prepara o indivíduo para a prática legal da cidadania, levando em consideração a importância do respeito e da interação nas sociedades adversas e em áreas distintas. A família não deve esquivar-se de uma tarefa primordial que lhe está confiada: a educação dos seus filhos. Ela pode viabilizar melhores condições de trabalho e preparar o indivíduo na construção da cidadania, como modo predominante, é indispensável à sociedade moderna.

Do ponto de vista pedagógico, o envolvimento da família na educação dos seus filhos é essencial para os seus desenvolvimentos cognitivo, social e cultural. Os pais tem as obrigações, previstas nos Projetos Políticos-Pedagógicos e nos Regimentos Escolares, de acompanhar, passo a passo, o processo de desenvolvimento educacional dos seus filhos. A política participativa dos pais no setor educacional, gera concordância, entusiasmo e incentivo aos profissionais que dela fazem parte. Essa demonstração nada mais é do que uma injeção animadora para a escola, sobretudo, pelo cumprimento da participação democrática, cujos efeitos trarão os resultados almejados por toda a comunidade.

Para todos os efeitos, a parceria família/escola deve ser uma constante, independentemente, de qualquer coisa, porém em algumas circunstâncias, os professores necessitam dos pais, simplesmente quando deparam-se com dificuldades, sejam de aprendizagem dos alunos ou pela indisciplina dos mesmos. Os pais acham que tampou há necessidade de participar do processo educacional, sobretudo quando os seus filhos vão bem na escola. Em resumo, a colaboração da família nesse processo deve acontecer a qualquer custo, tendo em vista, ser condição imprescindível ao avanço educativo e para o cumprimento do currículo escolar.

\section{CONSIDERAÇÕES FINAIS}

A sociedade vive a era da informação, da tecnologia de ponta e da globalização e, portanto, exige um tipo de educação que atenda aos requisitos necessários para a inserção no mercado de trabalho e cumprimento legal do exercício da própria 
cidadania. Enquanto os indivíduos evidenciam uma acentuada diversidade social e cultural, onde, enquanto cidadãos, tentam aprender algo mais, com o intuito de exterminar a alienação e integrá-los de forma efetiva e democrática na sociedade, o sistema dribla esses objetivos com estratégias utópicas e alienadoras.

Em frente a tanto progresso e transformação, cabe ao indivíduo optar pela educação como trilha norteadora que o direciona ao cume mais cobiçado pela sociedade: a cidadania. O cidadão é o ente fundamental para uma sociedade justa e igualitária, uma vez que ele cumpre com os seus deveres e exige os seus direitos com embasamentos na lei.

A educação deve ser aquela que educa para uma deliberação individual e democrática, com alargamento da cultura e construção consolidada da cidadania. Ela desempenha um papel extraordinário na produção e reprodução cultural, social e ética. Inicia-se na família, lócus berçal, das condições básicas de toda a vida social e produtiva.

Admite-se que a ausência da cidadania na sociedade hodierna, é resquício de uma educação saturada que vem demonstrando grande fomentação numerológica e uma ganância imensurável por estatística que venham favorecer satisfação à mídia deixando de cumprir com o seu papel primordial que é a formação qualitativa do indivíduo. Portanto, como é que este vai exercê-la se, no entanto, não adquiriu conhecimentos suficientes para o seu cumprimento?

Considerando ser a educação a única e exclusiva alternativa para a construção da cidadania e qualificação para o trabalho, torna-se necessário dar ênfase a mesma, exigindo a sua ampliação qualitativa através do cumprimento integral das leis que os asseguram.

\section{REFERÊNCIAS}

DUARTE, Newton. Educação escolar, teoria do cotidiano e a Escola de Vigotski.

2. ed. São Paulo: Autores Associados, 1999. 
FERGUSON, Marilyn. A conspiração aquariana. 7. Ed. Rio de Janeiro: Record, 1992.

FREIRE, Paulo. Pedagogia do oprimido. 21. ed. Rio de Janeiro: Paz e Terra, 1997.

TIBA, Içami. Professor, médico psiquiatra; Quem Ama Educa. Ed. Gente, 160ª - ed. 2004.

MOREIRA, Antônio Flávio Barbosa e CANDAU, Vera Maria. Indagações sobre Currículo, Conhecimento e Cultura. Brasília: Ministério da Educação, Secretaria de Educação Básica. 2008, 48. P.;

REVISTA, Faz Ciência, 08,01 (2006) pp. 291-306 UNIDOESTE ISSN 1677-0439.

SAVIANI, Demerval. Pedagogia histórico-crítica: primeiras aproximações. 5. ed. Campinas: Autores Associados, 1995.

TAMARIT, José. Educar o soberano. São Paulo: Cortez, 1996. 